JPE 11-6-11

\title{
A Study on Sensorless Control of Transverse Flux Rotating Motor Based on MRAS with Parameter Estimation
}

\author{
Jiwon Kim*, Kwangwoon Kim**, Dragos Ovidiu Kisck**, \\ Dohyun Kang*, Junghwan Chang ${ }^{\ddagger}$, and Jangmok Kim ${ }^{\dagger}$ \\ ${ }^{*}$ Industry Applications Research Laboratory, Korea Electrotechnology Research Institute, Changwon, Korea \\ ${ }^{* *}$ LG Industrial Systems, Korea \\ *** University POLITEHNICA of Bucharest, Bucharest, Romania \\ $¥$ Dept. of Electrical and Electronics Eng., Dong-A University, Busan, Korea \\ ${ }^{\dagger}$ Dept. of Electrical Eng., Busan National University, Busan, Korea
}

\begin{abstract}
This paper presents a sensorless control and parameter estimation strategies for a Transverse Flux Rotating Motor (TFRM). The proposed sensorless control method is based on a Model Reference Adaptive System (MRAS) to estimate the stator flux. Parameter estimation theory is also applied into the sensorless control method to estimate motor parameters, such as inductances. The effectiveness of the proposed methods is verified by some simulations and experiments.
\end{abstract}

Key Words: Model Reference Adaptive System (MRAS), Parameter Estimation, Sensorless Control, Transverse Flux Rotating Motor (TFRM)

\section{INTRODUCTION}

In the area of industrial applications, there are considerable demands for direct drives in order to avoid drawbacks of gear configurations, elasticity and backlash. Since the TFRM features a high flux concentration with high-energy density permanent magnets, it is a good candidate for the direct drive applications [1], [2].

In order to control stator current vectors suitably and to achieve high-performance drives, the information of rotor position and speed are necessary. In most variable-speed drives, some type of shaft sensor such as an optical encoder or resolver is connected to the rotor shaft. However, such sensors present several disadvantages such as high drive cost, large machine size, low reliability, and low noise immunity. Therefore the sensorless control of TFRM is desired, and various sensorless control strategies have been investigated, such as extended Kalman filter, high-frequency signal injection, observer - based position and speed estimators, etc [3],

\footnotetext{
Manuscript received Dec. 24, 2010; revised Sep. 27, 2011

Recommended for publication by Associate Editor Kyeong-Hwa Kim.

$\dagger$ Corresponding Author: jmok@pusan.ac.kr

Tel: +82-51-510-2366, Fax: +82-51-513-0212, Busan Nat'l University

* Industry Applications Research Laboratory, Korea Electrotechnology Research Institute, Changwon, Korea

** LG Industrial Systems, Korea

*** University POLITEHNICA of Bucharest, Bucharest, Romania

*Dept. of Electrical and Electronics Eng., Dona-A University, Korea
}

[4].

In the proposed strategy in this paper, the approach of wide speed sensorless control of TFRM is presented by using MRAS method. In as much as motor parameters are changed by magnetic saturation and temperature, etc., a position estimation error can be generated when there are differences between actual motor parameters and ones used in the estimation system. Especially, since the TFRM has the flux concentration structure, the flux can be saturated easily, which can cause the parameter variation. To maintain the estimation accuracy, a parameter identification method is applied. The daxis inductance and the q-axis inductance are estimated using recursive least square method, and the estimates are used in the MRAS sensorless control strategy.

This paper is configured as follows. First, the mathematical modeling is defined for sensorless strategy. Second, a parameter identification method is proposed. Finally, the effectiveness of the sensorless control and parameter estimation method are verified by some simulation and experiment results for TFRM.

\section{Mathematical Modeling for MRAS}

The voltage equations for the motor in the stator oriented coordinate system are written as (1) and (2).

$$
V_{s \alpha}=r_{s} i_{s \alpha}+\frac{d \lambda_{s \alpha}}{d t}
$$




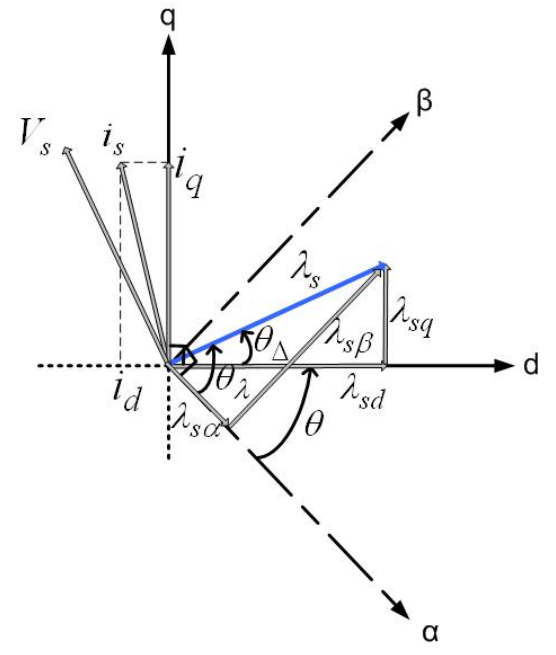

Fig. 1. Vector diagram of TFRM.

$$
V_{s \beta}=r_{s} i_{s \beta}+\frac{d \lambda_{s \beta}}{d t} .
$$

The flux equations in the rotor oriented coordinate system revolving the estimated angle $\hat{\theta}$ are expressed as (3), (4).

$$
\begin{gathered}
\lambda_{s d}=L_{d} i_{s d}+\lambda_{P M} \\
\lambda_{s q}=L_{q} i_{s q} .
\end{gathered}
$$

Fig. 1 shows the vector diagram of TFRM to estimate the rotor position $\theta$. Depending on a reference frame of stator flux, it can be expressed as $\theta_{\Delta}$ and $\theta_{\lambda}$. That is, $\theta_{\Delta}$ and $\theta_{\lambda}$ are the positions of the stator flux on the basis of the stator and the rotor oriented coordinate respectively. The method for estimating rotor position $\theta$ can be presented as (5). Also, the information of angles of $\theta_{\Delta}$ and $\theta_{\lambda}$ are expressed as (6) and (7).

$$
\begin{gathered}
\theta=\theta_{\lambda}-\theta_{\Delta} \\
\theta_{\lambda}=\tan ^{-1}\left(\frac{\lambda_{s \beta}}{\lambda_{s \alpha}}\right) \\
\theta_{\Delta}=\tan ^{-1}\left(\frac{\lambda_{s q}}{\lambda_{s d}}\right)
\end{gathered}
$$

In (6) and (7), to identify the information of $\theta_{\Delta}$ and $\theta_{\lambda}$, it is necessary to estimate the stator flux depending on a reference frame. Fig. 2 presents the block diagram of the proposed MRAS method to derive the stator flux. The outputs of the reference and adaptive model are $\left(\lambda_{s \alpha}^{*}, \lambda_{s \beta}^{*}\right)$ and $\left(\lambda_{s \alpha}\right.$, $\left.\lambda_{s \beta}\right)$, respectively. In the reference model, the original outputs are compensated by the outputs of the PI controllers which correct the stator flux error. And the estimated position $\hat{\theta}$ can be generated from the outputs of the reference model. The estimated position adjusts the adaptive model, and the outputs of the adaptive model compensate the outputs of the reference model.

\section{Parameter Estimation}

The applied method estimates unknown parameters using known values such as currents and voltages [5], [6]. The mathematical equation is constructed on an estimated rotating

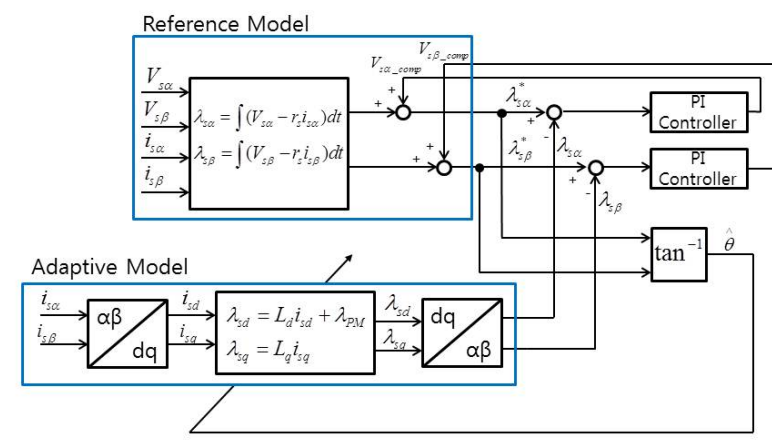

Fig. 2. Block diagram of the proposed MRAS.

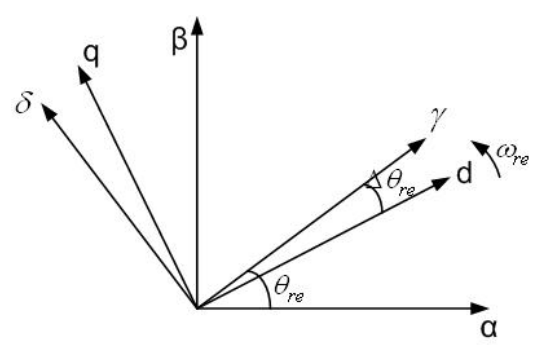

Fig. 3. Estimated vector diagram.

reference frame using Fig.3. Because the model coefficients can be assumed to be almost constant regardless of the rotating conditions [7]. A mathematical equation of TFRM on rotating reference frame is written as (8).

$$
\left[\begin{array}{l}
V_{d} \\
V_{q}
\end{array}\right]=\left[\begin{array}{cc}
r_{s}+p L_{d} & -\omega L_{q} \\
\omega L_{d} & r_{s}+p L_{q}
\end{array}\right]\left[\begin{array}{c}
i_{d} \\
i_{q}
\end{array}\right]+\omega \lambda_{P M}\left[\begin{array}{l}
0 \\
1
\end{array}\right]
$$

By changing (8) to the one on the estimated rotating reference frame, and changing the equation to a discrete state equation, it is expressed as (9).

$$
\left[\begin{array}{c}
i_{\gamma}(k) \\
i_{\delta}(k)
\end{array}\right]=A\left[\begin{array}{c}
i_{\gamma}(k-1) \\
i_{\delta}(k-1)
\end{array}\right]+B\left[\begin{array}{c}
V_{\gamma}(k-1) \\
V_{\delta}(k-1)
\end{array}\right]+C\left[\begin{array}{l}
1 \\
1
\end{array}\right]
$$

where,

$$
\begin{gathered}
A=\left[\begin{array}{ll}
a_{11} & a_{12} \\
a_{21} & a_{22}
\end{array}\right]=\left(1-\frac{r_{s} l_{0} T_{s}}{L_{d} L_{q}}\right) I+\frac{r_{s} l_{1} T_{s}}{L_{d} L_{q}} Q\left(2 \Delta \theta_{r e}\right) \\
+\frac{\omega\left(L_{d}^{2}+L_{q}^{2}\right) T_{s}}{2 L_{d} L_{q}} J-\frac{\omega\left(L_{d}^{2}+L_{q}^{2}\right) T_{s}}{2 L_{d} L_{q}} S\left(2 \Delta \theta_{r e}\right) \\
B=\left[\begin{array}{ll}
b_{11} & b_{12} \\
b_{21} & b_{22}
\end{array}\right]=\frac{l_{0} T_{s}}{L_{d} L_{q}} I-\frac{l_{1} T_{s}}{L_{d} L_{q}} Q\left(2 \Delta \theta_{r e}\right) \\
C=\left[\begin{array}{l}
c_{1} \\
c_{2}
\end{array}\right]=\frac{\omega \lambda_{P M} T_{s}}{L_{q}}\left[\begin{array}{c}
\sin \left(\Delta \theta_{r e}\right) \\
-\cos \left(\Delta \theta_{r e}\right)
\end{array}\right] \\
I=\left[\begin{array}{ll}
1 & 0 \\
0 & 1
\end{array}\right], J=\left[\begin{array}{cc}
0 & -1 \\
1 & 0
\end{array}\right] \\
Q\left(2 \Delta \theta_{r e}\right)=\left[\begin{array}{cc}
\cos \left(2 \Delta \theta_{r e}\right) & \sin \left(2 \Delta \theta_{r e}\right) \\
\sin \left(2 \Delta \theta_{r e}\right) & -\cos \left(2 \Delta \theta_{r e}\right)
\end{array}\right]
\end{gathered}
$$




$$
\begin{gathered}
S\left(2 \Delta \theta_{r e}\right)=\left[\begin{array}{cc}
-\sin \left(2 \Delta \theta_{r e}\right) & \cos \left(2 \Delta \theta_{r e}\right) \\
\cos \left(2 \Delta \theta_{r e}\right) & \sin \left(2 \Delta \theta_{r e}\right)
\end{array}\right] \\
l_{0}=\frac{\left(L_{d}+L_{q}\right)}{2}, l_{1}=\frac{\left(L_{d}-L_{q}\right)}{2} \\
T_{s}: \text { sampling time }
\end{gathered}
$$

Equation (9) is transformed as (10) to apply the recursive least square method.

$$
y=\Theta \cdot z
$$

where,

$$
\begin{aligned}
& y=\left[\begin{array}{ll}
i_{\gamma}(k) & i_{\delta}(k)
\end{array}\right]^{T} \\
& z=\left[\begin{array}{lllll}
i_{\gamma}(k-1) & i_{\delta}(k-1) & V_{\gamma}(k-1) & V_{\delta}(k-1) & 1
\end{array}\right]^{T} \\
& \Theta=\left[\begin{array}{lll}
A & B & C
\end{array}\right]=\left[\begin{array}{lllll}
a_{11} & a_{12} & b_{11} & b_{12} & c_{1} \\
a_{21} & a_{22} & b_{21} & b_{22} & c_{2}
\end{array}\right]^{T}
\end{aligned}
$$

Using equation (10), the unknown parameter matrix $\Theta$ can be obtained from known vector y and $z$. This method identifies the parameter matrix $\Theta$ as the square value of the prediction error reaches a minimum as (11).

$$
\varepsilon_{i}=(y-\Theta \cdot z)^{2}
$$

To estimate the parameter matrix $\Theta$, a recursive least square method is used as shown in (12) and (13).

$$
\begin{gathered}
\Theta(k)=\Theta(k-1)+[y-\Theta(k-1) \cdot z] \cdot z^{T} \cdot P(k) \\
P(k)=\frac{1}{\lambda}\left(P(k-1)-P(k-1) \cdot z \cdot\left(\lambda+z^{T} P(k-1) \cdot z\right)^{-1} \cdot z^{T} \cdot P(k-1)\right) .
\end{gathered}
$$

In the equation (12), the correction term $\left(z^{T} \cdot P(k)\right)$ is proportional to the difference between the measured value of $\mathrm{y}(\mathrm{t})$ and prediction of $\mathrm{y}(\mathrm{t})$ based on the previous parameter estimate. The components of the vector $\left(z^{T} \cdot P(k)\right)$ are weighting factors that tell how the correction and the previous estimation should be combined. And $\lambda$ is defined as the weighting coefficient, the role of which is to delete past data. However, it is difficult to derive motor parameters from the estimated matrix $\Theta$. The equation (14) is defined from characteristics of the parameter matrix $\Theta$. Using these characteristics, motor parameters can be derived as (15).

$$
\begin{gathered}
E_{1}=b_{11}+b_{22}=\frac{2 l_{0}}{L_{d} L_{q}} T_{s} \\
E_{2}=a_{11}+a_{22}-2=-\frac{2 r_{s} l_{0}}{L_{d} L_{q}} T_{s} \\
E_{3}=\sqrt{\left(b_{11}-b_{22}\right)^{2}+\left(b_{12}+b_{21}\right)^{2}}=-\frac{2 l_{1}}{L_{d} L_{q}} T_{s} \\
\hat{L}_{d}=\frac{2 T_{s}}{E_{1}+E_{3}} \\
\hat{L}_{q}=\frac{2 T_{s}}{E_{1}-E_{3}}
\end{gathered}
$$

Fig. 4 shows the block diagram of parameter estimation. In the Fig. 4 White Gaussian Noise (WGN) is injected to identify motor parameter well. The algorithm for generating WGN is the kinds of remainder to derive the linear congruent sequence. In addition, the identified parameters pass through a low-pass filter.

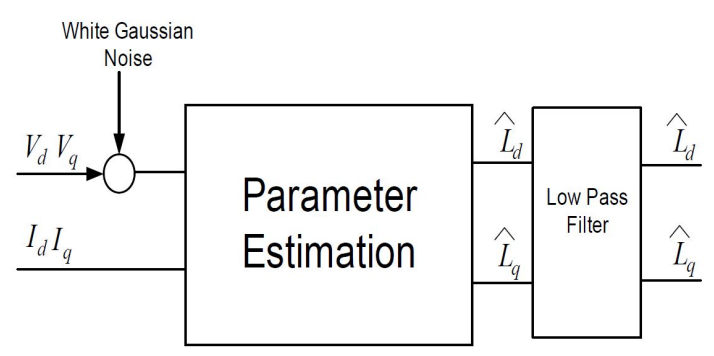

Fig. 4. Block diagram of parameter estimation.

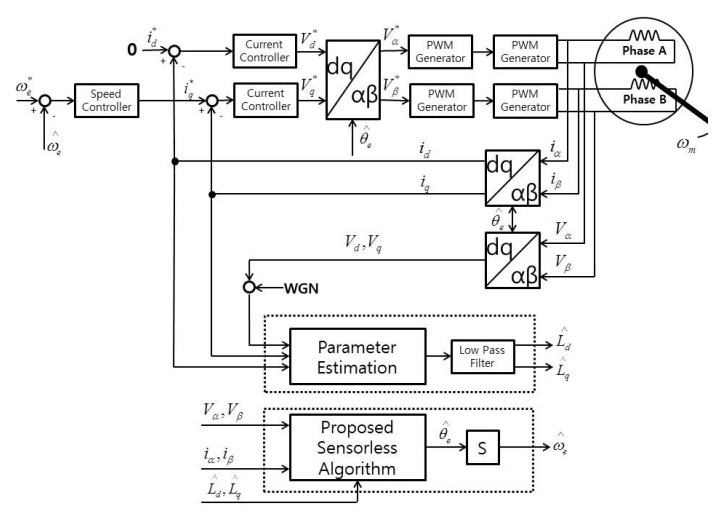

Fig. 5. Block diagram of sensorless speed control.

\section{Dynamic Simulation}

\section{A. Dynamic Simulation Configuration}

The dynamic simulation has been performed for the verification of the proposed strategies. The characteristics of TFRM can be non-linear easily due to the structure of flux concentration. To reduce the modeling error, analyzed 3DFEM data was used for TFRM by using look-up table [8]. And, the applied motor model has two phases with angle difference of 90 degree. This structure is more convenient when organizing the $\mathrm{d}-\mathrm{q}$ control schemes on the grounds that it basically has $\alpha-\beta$ frames. Fig. 5 indicates the block diagram of sensorless speed control including the sensorless algorithm and parameter estimation.

In Fig. 5, d-axis current was controlled by zero value after analyzing the MTPA strategy [9]. Also, in the part of parameter estimation and sensorless control, Matlab /C-mex method is used for applying experiment immediately.

The specifications of the applied TFRM are listed in Table I.

\section{B. Dynamic Simulation Results}

In the Dynamic Simulation, the results represents only if the strategies are reasonable or not, since the iron losses are not

TABLE I

MOTOR SPECIFICATIONS

\begin{tabular}{|l|l|}
\hline Rated power & $1.3 \mathrm{~kW}$ \\
Rated torque & $52 \mathrm{~N} \cdot \mathrm{m}$ \\
Rated speed & $250 \mathrm{rpm}$ \\
Number of pole-pairs & 30 \\
Phase number & 2 \\
Rated current & $6 \mathrm{Arms}$ \\
Phase resistance & $0.56 \mathrm{Ohm}$ \\
d-axis inductance & $16 \mathrm{mH}$ \\
q-axis inductance & $18 \mathrm{mH}$ \\
\hline
\end{tabular}




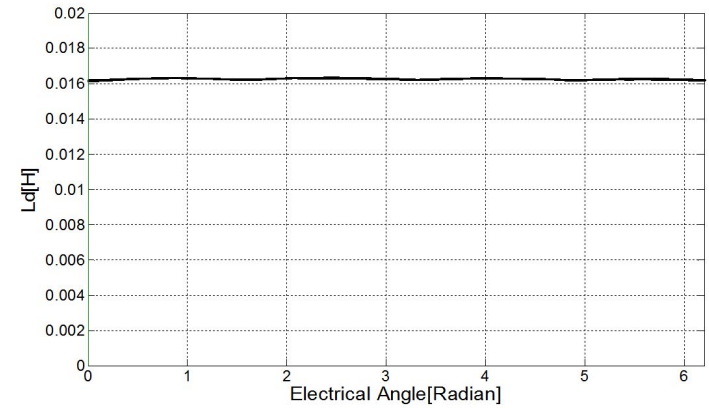

(a)

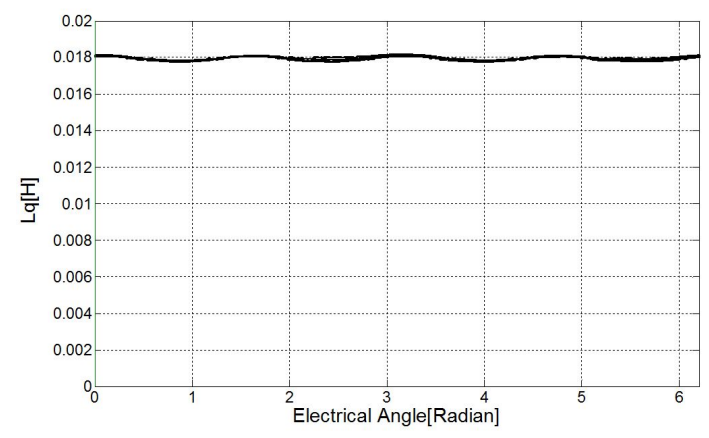

(b)

Fig. 6. Estimated inductance from dynamic simulation. (a) d-axis inductance (b) q-axis inductance.

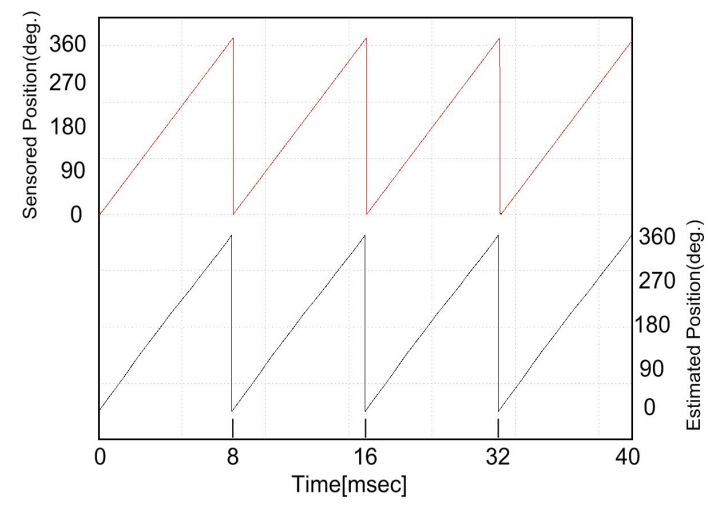

Fig. 7. Measured position and estimated position.

considered. Fig. 6 represents the estimated inductance each. From the Table I, the value of inductance are $16[\mathrm{mH}]$ and $18[\mathrm{mH}]$ respectively. The result of parameter estimation was also found with same value.

The proposed sensorless algorithm is proved in dynamic simulation result as Fig. 7. The result was obtained from condition of steady-state (250 rpm, 0Nm).

\section{EXPERIMENTAL RESULTS}

\section{A. Experimental Test Set-up}

The proposed sensorless speed control system is expressed as Fig. 5. The algorithms are implemented on a Texas Instruments TMS320VC33 floating-point digital signal processor (DSP). In addition, Table II shows the drive specifications applied in the experiment.

The applied strategies for parameter estimation and sensorless control method should have the considerations for
TABLE II

DRIVE SPECIFICATIONS

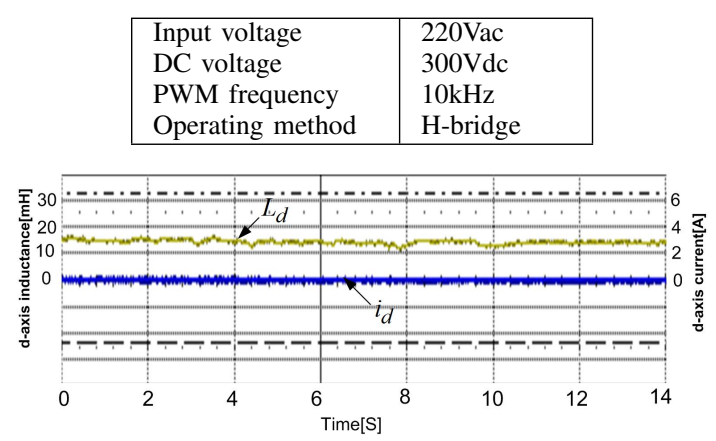

(a)

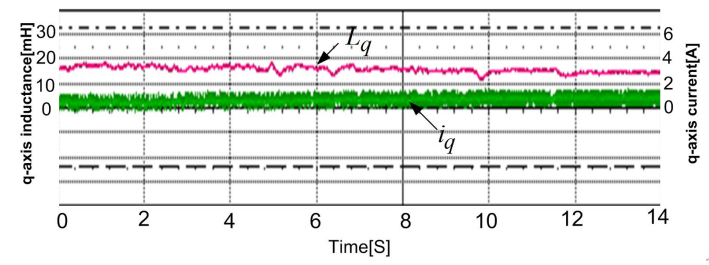

(b)

Fig. 8. Estimated parameters in case of $250[\mathrm{rpm}]$ and no-load condition. (a) Estimated d-axis inductance. (b) Estimated q-axis inductance.

implementation time. Especially, because the parameter estimation method has the complicated matrix calculation, it was performed with optimized method to reduce the operating time. As a result, the total control time were 80[us] including speed controller and parameter estimation, etc. This time is enough to operate inside the sampling time 100 [us]. What is more, when it comes to control gain of parameter estimation in the experiments, there are some factors to consider it. First, in the equation (13), the weighting $\operatorname{coefficient}(\lambda)$ is determined as relationship of (16)[10].

$$
\lambda=e^{-h / T_{f}}
$$

where $h$ : sampling period,

$T_{f}$ : time constant for the exponential forgetting

From equation (16), the applied gain $(\lambda)$ is selected as 0.87 using parameter $\left(h=0.0001[\mathrm{~s}], \mathrm{T}_{\mathrm{f}}=0.0007[\mathrm{~s}]\right)$. Second, the cutoff frequency of a low-pass filter in the estimated parameter is selected as $18.85[\mathrm{rad} / \mathrm{s}]$.

\section{B. Parameter Estimation Results}

Fig. 8 shows the experimental results of parameter estimation in case of no-load condition. In comparison with the simulation results, the estimated parameter is nearly same. But as the speed is increased, q-axis inductance tends to decrease due to the iron losses.

Fig. 9 demonstrates the test results of load condition. By adding the load torque, $\mathrm{q}$-axis current was increased to generate an electromagnetic torque. At the same time, q-axis inductance is saturated as Fig.9-(b).

\section{Sensorless Speed Control Results}

Fig. 10 presents the performance of estimated position and speed in condition of no load using proposed sensorless method. 


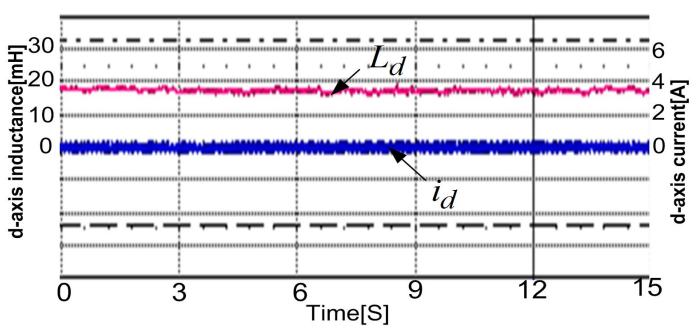

(a)

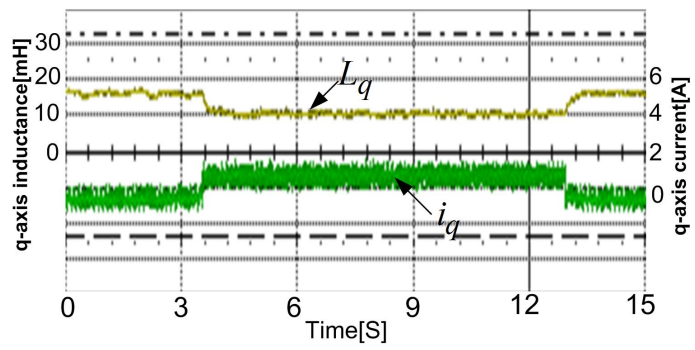

(b)

Fig. 9. Estimated parameters in case of $250[\mathrm{rpm}]$ and $10[\mathrm{Nm}]$. (a) Estimated d-axis inductance. (b) Estimated q-axis inductance.

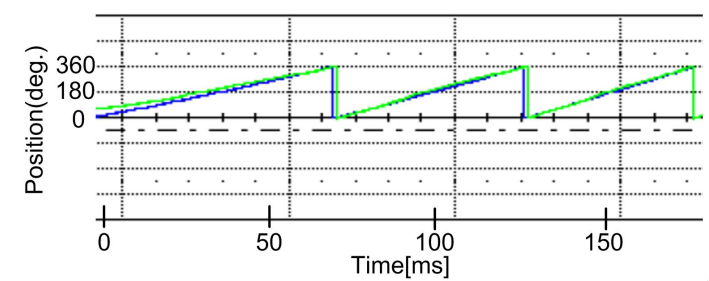

(a)

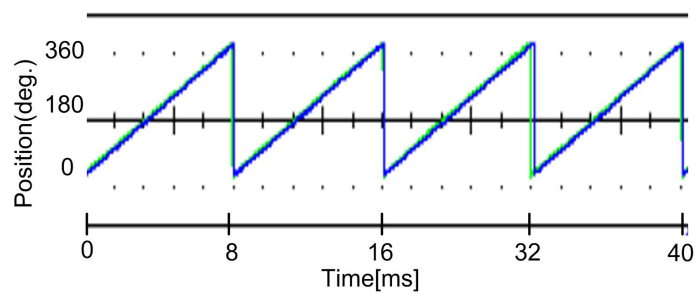

(b)

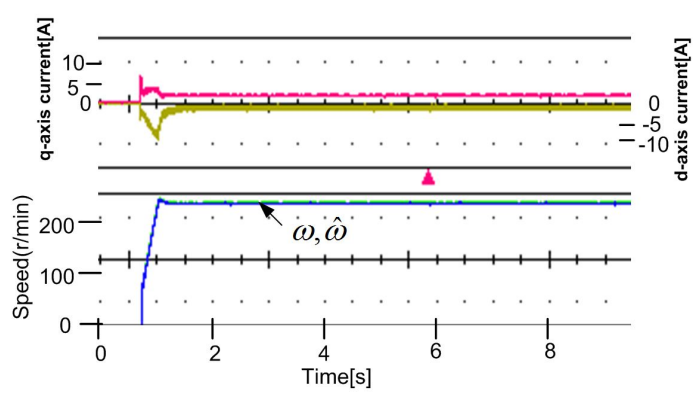

(c)

Fig. 10. Estimated position and speed in case of no-load. (a) Initial performance. (b) Steady-state performance. (c) Acceleration performance from $0[\mathrm{rpm}]$ to $250[\mathrm{rpm}]$.

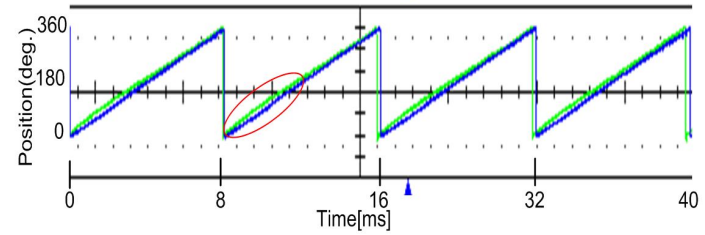

(a)

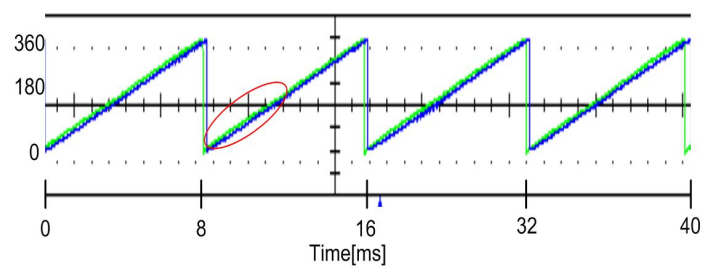

(b)

Fig. 11. Estimated position in case of $250[\mathrm{rpm}]$ and $10[\mathrm{Nm}]$. (a) Without parameter estimation. (b) With parameter estimation.

Fig. 11 represents the results of estimated position in case of load condition without and with the parameter estimation. From Fig. 11, the q-axis inductance is changed when load is added. This change of the parameter can cause a position error shown in Fig. 11(a). After adding the parameter estimation, the position error was reduced by Fig. 12(b).

\section{CONClusions}

This paper proposes a novel sensorless control strategy for TFRM, which is based on a MRAS using stator flux. To prove the proposed sensorless method, the dynamic simulation and experiment is implemented. In addition, considering the saturation of TFRM, the parameter estimation is applied to reduce the position and speed errors. As a result, the effectiveness of proposed sensorless algorithm is verified. Also, adding the parameter estimation has a good performance in the sensorless method.

\section{REFERENCES}

[1] D. H. Kang and H. Weh, "Design of an integrated propulsion, guidance, and levitation system by magnetically excited transverse flux linear motor (tfm-lm)," IEEE Trans. Energy Convers., Vol. 19, No. 3, pp.477484, Sep. 2004.

[2] D. H. Kang, Y. H. Chun, and H. Weh "Analysis and optimal design of transverse flux linear motor with PM excitation for railway traction," IEEE Proceeding of Electric Power Application, Vol. 150, No. 4, pp.493499, 2003.

[3] S. Ogasawara and H. Akagi, "Implementation and position control performance of a position-sensorless IPM motor drive system based on magnetic saliency," IEEE Trans. Ind. Applicat., Vol. 34, No. 4, pp. 806812, Jul./Aug. 1998.

[4] N. Ertugrul and P. Acarnley, "A new algorithm for sensorless operation of permanent magnet motors," IEEE Trans. Ind. Applicat., Vol. 30, No. 1, pp. 126-133, Jan./Feb. 1994.

[5] A. Iwata, S. Ichikawa, M. Tonita, S. Doki, and S. Okuma, "Position and velocity sensorless control of SynRMs using on-line parameter identification," IECON'03, Vol 3, pp.2156-2161, 2003.

[6] S. Ichikawa, A. Iwata, M. Tonita, S. Doki, and S. Okuma, "Sensorless control of synchronous reluctance motors using an on-line parameter identification method taking into account magnetic saturation," PESC'04, Vol 5, pp. 3311-3316, 2004.

[7] S. Ichikawa, M. Tonita, S. Doki, and S. Okuma, "Sensorless control of permanent-magnet synchronous motors using online parameters identification based on system identification theory," IEEE Trans. Ind. Electron., Vol. 53, No. 2, pp. 363-372, Apr. 2006 
[8] K. W. KIM, J. W. KIM, Y. H. Jung, J. Y. Lee, D. H. Kang, and J. H. Chang, "Inductance estimation of permanent magnet type transverse flux rotating motor using dynamic-simulation," KIEE Trans. Vol. 59, No. 4, pp.722-727, Apr. 2010

[9] C.-T. Pan and S.-M. Sue "A linear maximum torque per ampere control for ipmsm drives over full-speed range," IEEE Trans. Energy Convers., Vol. 20, No. 2, pp. 359-366, Jun. 2005

[10] K. J. Astrom and B. Wittenmark, ADAPTIVE CONTROL, pp. 465-480.

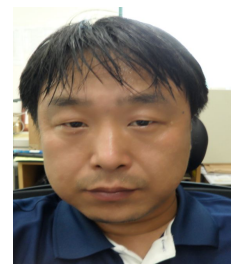

Jiwon Kim was born in Seoul, Korea, in 1971. He received the B.S. and M.S. degrees in control and instrumentation engineering from the University of Seoul and Kwang-Woon University, Seoul, Korea, in 1994 and 1996, respectively. He is currently working toward the $\mathrm{Ph} . \mathrm{D}$. degree at Pusan National University. Since 1996, he has been with Korea Electrotechnology Research Institute (KERI). His research interests are in the areas of power electronics control of electric machines, electric propulsion, and power quality.

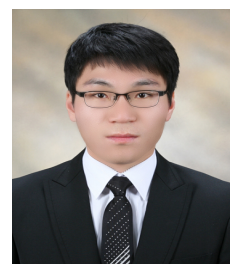

Kwangwoon Kim was born in Korea in 1982. He received the B.S. degree in electrical engineering from Kangwon National University, Chuncheon, Korea in 2008, the M.S. degree in energy conversion from the University of Science \& Technology, Daejeon, Korea in 2010. Currently, he is a EV control team member of LS industrial System. He is engaged in research on motor control and design for EV systems.

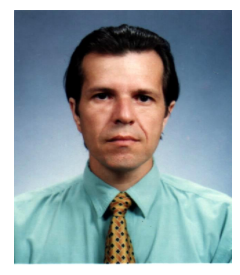

Dragos Ovidiu Kisck was born in Brasov, Romania, in 1957. He received the B.S., M.S., and Ph.D. degrees from University Poliyehnica of Bucharest, Romania in 1982, 1984 and 1995 respectively. He worked as Design Engineer in Electical Research Institute of Bucharest from from 1980 until 1986. Since 1987 he has been with the University Politehnica of Bucharest, Romania, as professor on Electrical Engineering Faculty. He was inviting as visiting professor at some European and Asian universities and research scientist of Korea Electrotechnology Research Institute. He is the director of the DSP Control of Electrical Drives Laboratory. His research interests are in the area of digital control of electrical drives, power quality, and design of electrical machines. He is member of EPE and IEEE.

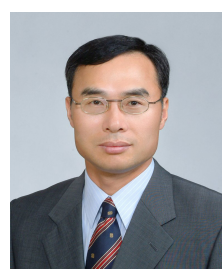

Dohyun Kang was born in Gyungnam, Korea, in 1958. $\mathrm{He}$ received the B.S. and M.S. degrees in electrical engineering from the Hanyang University, Seoul, Korea, in 1981 and 1989, respectively, and Ph.D. degrees from Braunschweig University, German in 1996. From 1981 to 1987, he worked at the HYUNDAI Engineering \& Construction. Since 1989, he has been with Korea Electrotechnology Research Institute(KERI), where he is currently executive director of Industry Applications Research Division. His research interests are in design of transverse flux machine.

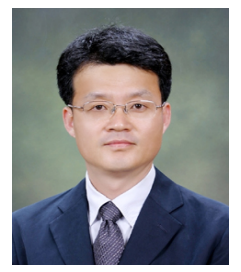

Junghwan Chang was born in Busan, Rep. of Korea in 1968. He received B. S. and M.S. degrees in electrical engineering and Ph.D. degree in precision mechanical engineering from Hanyang University, Seoul, Rep. of Korea in 1994, 1997 and 2001, respectively. From 2001 to 2002, he worked at Institute of Brain Korea 21 at Hanyang University, where he developed micro drive and high-speed spindle motor. From 2002 to 2003, he worked as research fellow at University of California at Berkeley with the support of Korea Science and Engineering Foundation, and analyzed and developed electrically controlled engine valve system. From 2003 to 2009, he worked in Korea Electrotechnology Research Institute (KERI) as a senior researcher, and engaged in the developments of special purpose machines. Since 2009 , he has been with the department of electrical engineering, Dong-A University, Busan Rep. of Korea, as a assistant professor. His interests are the design and analysis of electro-mechanical systems including driving circuits.

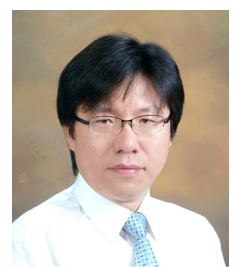

Jangmok Kim was born in Busan, Korea, in 1961. He received the B.S. degree from Pusan National University (PNU), Busan, in 1988, and the M.S. and Ph.D. degrees from the Department of Electrical Engineering, Seoul National University, Seoul, Korea, in 1991 and 1996 , respectively. From 1997 to 2000, he was a Senior Research Engineer with Korea Electrical Power Research Institute. Since 2001, he has been with the Department of Electrical Engineering, PNU, where he is currently a Faculty and a Research Member in the Research Institute of Computer Information and Communication. His research interests include the control of the electric machines, electric vehicle propulsion, and power quality. 